\title{
AC 2011-2492: A DESIGN OF SUSTAINABLE ENERGY LABORATORY
}

\section{Linfeng Zhang, University of Bridgeport}

Linfeng Zhang is an Assistant Professor in the Department of Electrical Engineering at the University of Bridgeport. He obtained his Ph.D. from Wayne State University. His current research is on the renewable energy, power system, and electronic devices.

\section{Xingguo Xiong, University of Bridgeport}

Xingguo Xiong is an assistant professor in Department of Electrical and Computer Engineering, University of Bridgepeort, Bridgeport, CT 06604. His research areas include Microelectromechanical System (MEMS), nanotechnology, as well as VLSI design and testing.

\section{Dr. Navarun Gupta, University of Bridgeport}

Navarun Gupta (navarung@bridgeport.edu) is an Assistant Professor in the Department of Electrical and Computer Engineering at the University of Bridgeport, Connecticut. He is also the Associate Chair of the Electrical Engineering department. He received a Ph.D. from Florida International University in 2003. His interests include the application of digital signal processing in acoustics and bio-signals. 


\title{
A design of sustainable energy laboratory
}

Linfeng Zhang An assistant professor of Electrical Engineering at University of Bridgeport. His research interests are in sensors and actuators, sustainable energy.

\section{Xingguo Xiong, University of Bridgeport}

An assistant professor of Electrical Engineering at University of Bridgeport. His research interests are in MEMS, nanotechnology, VLSI.

\begin{abstract}
Sustainable energy, including solar power, wind power, and geothermal power, is very attractive since the utilization of sustainable resources can significantly decrease the emission and protect our environment. Also, the use of such energy can enhance the national energy security and reduce the dependence on the imported fossil fuel.

Till now, several energy-related courses, such as Fuel Cells, Sustainable Energy, and Hybrid Vehicles, have been offered at the University of Bridgeport. In order to have hands-on experience, a laboratory is necessary for our engineering students with their interest in the sustainable energy as well as smart grid. A course, Sustainable Energy Laboratory, was proposed by the school's curriculum committed and it is offered in the Spring semester, 2011. In this course, a series of experiments are designed on the operating and testing of solar panels, wind turbine, fuel cell. Moreover, experiments on power electronics and data acquisition are developed to optimize the utilization of different energy sources. Finally, simulation on smart grid power system and hybrid power system will help the students understand the challenges in the use of sustainable energy resources.
\end{abstract}




\section{Introduction}

The original motivation for sustainable energy came from our research on hydrogen sensors for hydrogen-fuel-cell vehicles. Besides the important role of hydrogen in the utilization of sustainable energy, the advantages of sustainable energy over fossil fuel are much clear with its effect on the environment as well as our economy. Moreover, it is important to understand finance and public policy in adopting sustainable energy.

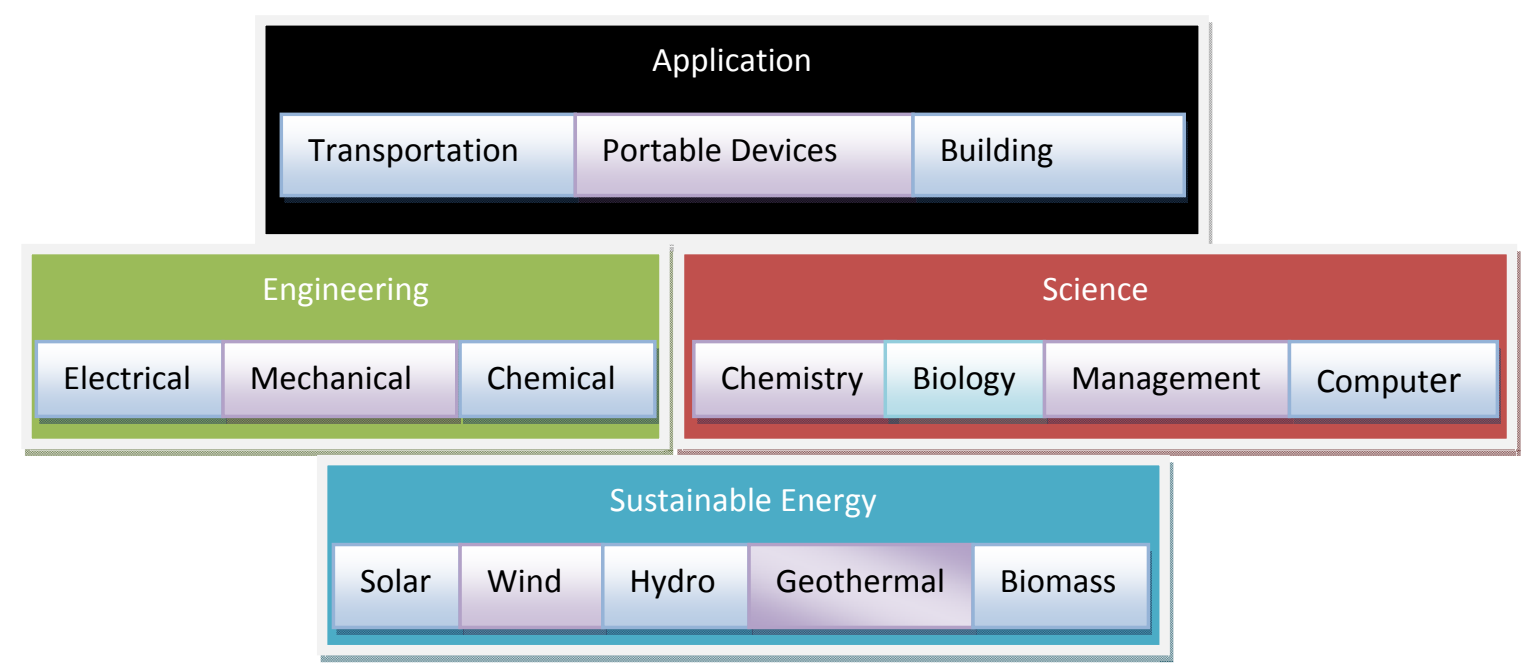

Figure 1. Sustainable energy lies at the interaction of several engineering and scientific fields

Sustainable energy is an emerging interdisciplinary field and it is related to multiple deciplines as shown in Figure 1. The energy-related courses are provided in Electrical Engineering, Mechanical Engineering, Chemistry, and business. In our Electrical Engineering Department, Sustainable Energy (ELEG 490), Sustainable Energy Laboratory (ELEG492), Fuel Cells (ELEG419), and Hybrid Vehicles (ELEG 493) have been offered for two years. During our teaching, the interdisciplinary nature of sustainable energy brings tremendous challenges. Firstly, there is no well designed text book and the instructor has to prepare his/her lecture notes, design homework problems, and provide solution manual. Secondly, the knowledge framework or set of the sustainable energy need to be summarized to make a efficient education. Thirdly, it is hard for the students in one major to understand some fundamental theories or topics in another major. The instructor should pay attention to the students' feedback and dynamically clarify the doubts in the teaching accordingly. Fourthly, different methods, including workshop, should be used to inspire the students.

In order to have some hands-on experience, a Renewable Energy Research Laboratory began to be established with the support from UB Seed Money Grants and U.S. Departmen of Energy sub-award. This comes up with a new course, Sustainable Energy Laboratory (EE492). This is a 3 credit graduate laboratory with the capacity as 15 . The experiments in this lab are designed to enhance the students' hands-on experience in the energy-related development and research. At the end of the course, the students are expected to be able to

o Estimate the solar irradiance on solar panels, set up solar panels, and evaluate their performance 
o Estimate the wind energy, understand the working principle of wind turbine, and evaluate its performance

o Understand the working principles of fuel cell and electrolyzer, set up these instruments, evaluate their performance

o Design, simulate, and optimize energy systems for home or small community

\section{The setup of the laboratory and the design of the experiments}

Table 1 is the list of the hardware with the cost. For wind turbine, a pole and a stand were custom built and this wind turbine can be moved outside from the lab. Table 2 is the list of software used in the lab. There is no cost for LabVIEW since it is already in our school. HOMER is a software developed in National Renewable Energy Laboratory of US Department of Energy. It can be used to simulate hybrid power system and it is free of charge. SCAPS was developed in the University of Gent and it is used to design solar cell. It is free of charge too. SmartGrid is developed at University of Bridgeport and it can be downloaded from our website. In a word, the total cost of our Renewable Energy Research Laboratory is around \$20,000.

Table 1 List of the hardware in the lab

\begin{tabular}{|c|c|c|}
\hline Item & Quantity & Unit cost (\$) \\
\hline Wind turbine 1000W & 1 & 700 \\
\hline Hydrogen fuel cell & 2 & 90 \\
\hline Electrolyzer & 2 & 230 \\
\hline Power pole board & 2 & 1125 \\
\hline Solar digital meter & 1 & 155 \\
\hline Solar panel & 1 & 210 \\
\hline Function generator & 2 & 166 \\
\hline Resistance substitution box & 2 & 25 \\
\hline DC power supply & 4 & 60 \\
\hline Computer & 4 & 500 \\
\hline HP 4276A LCZ meter & 1 & already in lab \\
\hline Digital multimeter with RS232 & 4 & 70 \\
\hline
\end{tabular}

Table 2 List of the software in the lab

\begin{tabular}{|l|}
\hline \multicolumn{1}{|c|}{ Item } \\
\hline LabVIEW (National Instrument) \\
\hline Homer(National Renewable Energy Lab) \\
\hline SCAPS (University of Gent) \\
\hline SmartGrid (Renewable Energy Research Lab at UB) \\
\hline Microsoft Excel \\
\hline
\end{tabular}

In this lab, there are four experiments and two simulations.

* Experiment 1: Solar panel testing and solar cell simulation 

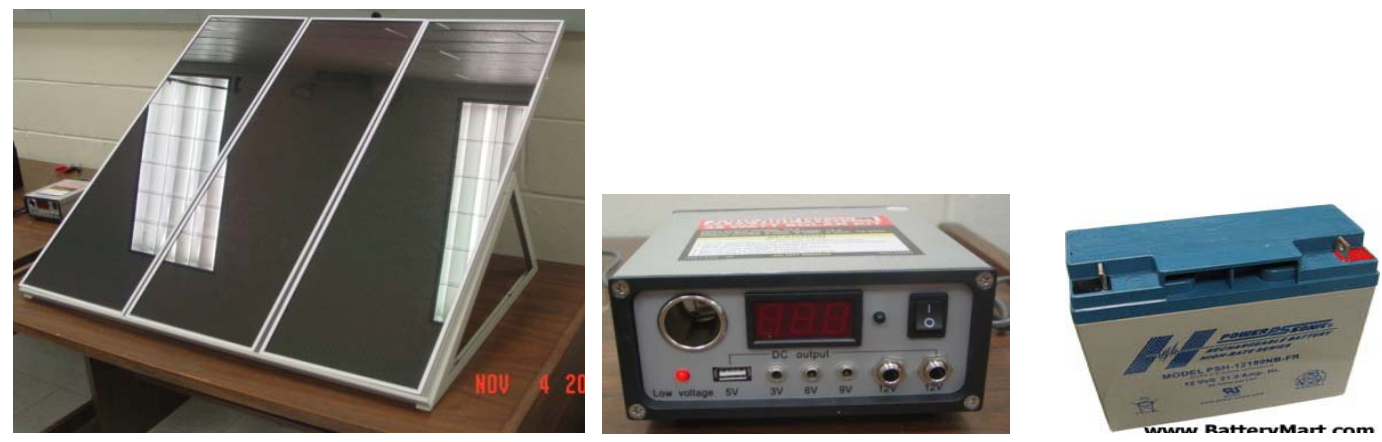

Figure 2 Solar panel, regulator, and rechargeable battery

The solar irradiance can be measured through a solar digital meter and this irradiance is used to determine the efficiency of the solar panel. The current-voltage curve of a solar panel can be obtained with a resistance substitution box. In this experiment, program in LabVIEW is also used to monitor the output from the solar panel.

* Experiment 2: Characterization of hydrogen fuel cell
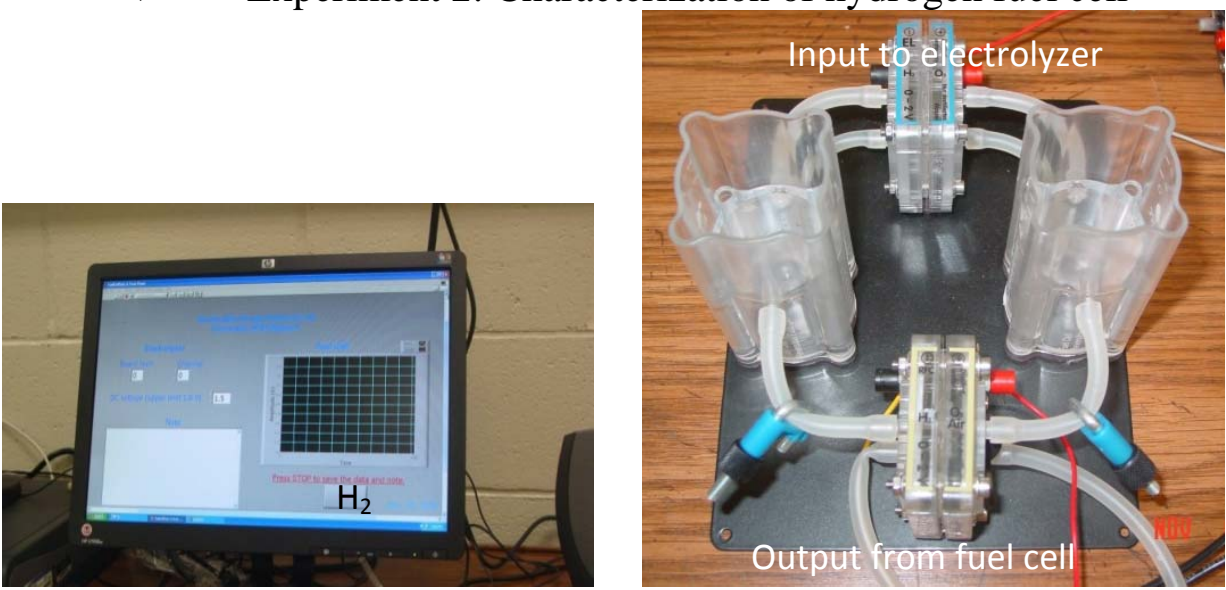

Figure 3 a fuel cell system with an electrolyzer

In this experiment, hydrogen is supplied to a hydrogen fuel cell by an electrolyzer. A multimeter is connected to a computer through a RS 232 cable and a program was developed in LabVIEW for data acquisition. Therefore, the output voltage will be displayed on the monitor and stored in the computer for data analysis. There is also a resistance substitution box as an external load, this makes it easy to obtain a current-voltage curve. Moreover, the transient response can be observed whenever the load is changed and some kind of overvoltage can be estimated. 

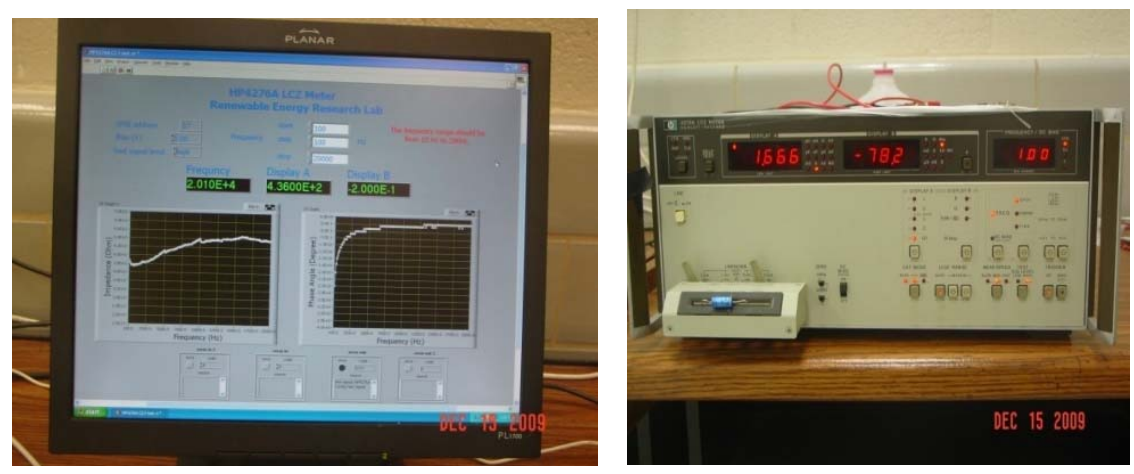

Figure 4 Impedance spectrum from fuel cell

In order to estimate the equivalent circuit of a fuel cell as well as different overvoltages, an impedance spectrum can provide necessary information . In this experiment, a HP LCZ meter is connected to a computer with a GPIB cable and a program in LabVIEW was developed for the control and data acquisition. When the fuel cell is supplied only hydrogen or oxygen, the impedance and phase angle are measured with the frequency range between $100 \mathrm{~Hz}$ and $20 \mathrm{kHz}$.

\section{* Experiment 3: Power Electronics}
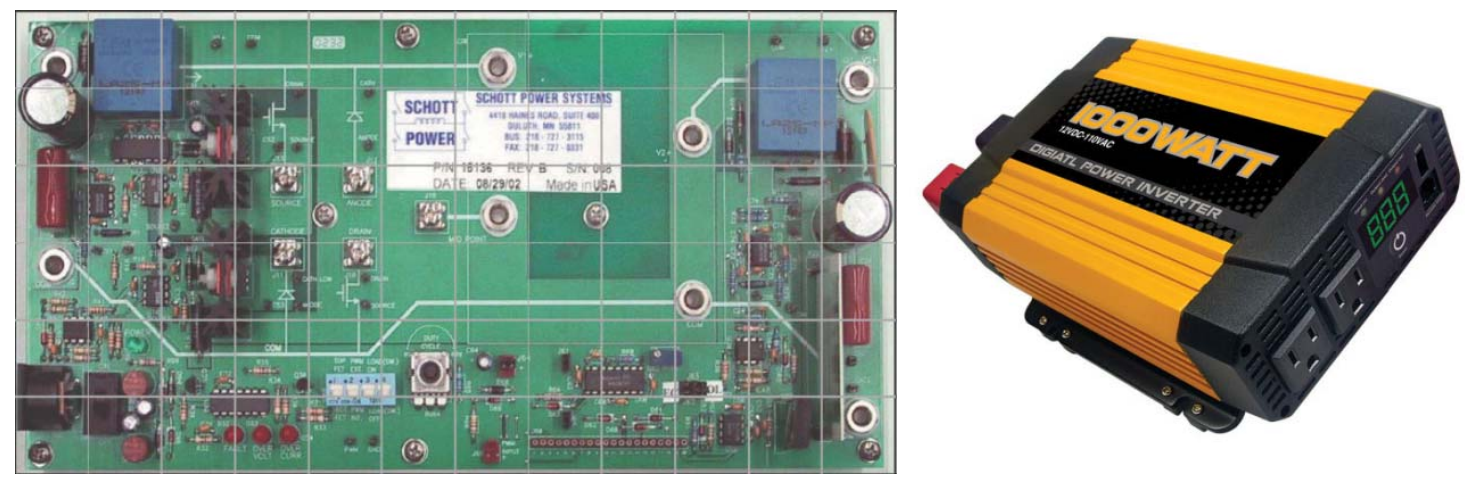

Figure 5 Power pole board and true sine wave inverter

The experiment design in the power electronics is from the manual prepared by Dr. Ned Mohan in the University of Minnesota [1]. In our course, experiment on Buck-booster converter will be carried out. Moreover, a pure-sine wave inverter will be used to convert DC to AC.

* $\quad$ Experiment 4: Wind turbine

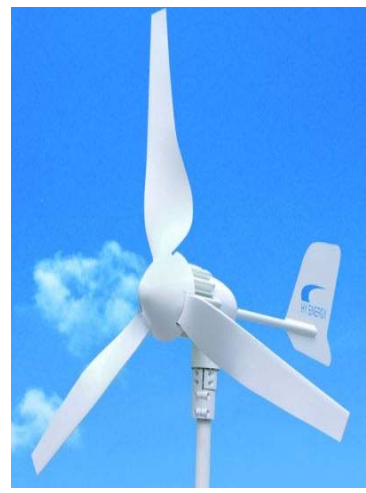


Figure 6 Wind turbine

In this experiment, a hybrid power system consists of wind turbine, solar panel, rechargeable lead acid battery, and dynamic load. The whole system will run with the control of the circuit breakers through LabVIEW program and the output from each power will be monitored. The objective of this experiment is to get familiar with the setup of the system and optimize the system for the best performance.

* Simulation 1: Power system with renewable energy resources

HOMER is a computer model that simplifies the task of evaluating design options for both off-grid and grid-connected power systems for remote, stand-alone, and distributed generation applications [2]. HOMER models both conventional and renewable energy technologies:

\section{Power sources:}

- solar photovoltaic (PV)

- wind turbine

- electric utility grid

- microturbine

- fuel cell

\section{Storage:}

- battery bank

- hydrogen

\section{Loads:}

- daily profiles with seasonal variation

In this simulation, the performance, emission, and cost of the power system can be calculated.

* Simulation 2: A smart grid with renewable energy resources

A JAVA program was developed to simulate a smart grid. In this simulation, a smart grid consists of multiple MGs and one power plant and its structure is shown in Figure 7 (a). The price on the central dispatch of the smart grid is dynamic, high in the day time and low in the night time. There is two-way transmission between the main dispatch and a microgrid. a performance metric $\mathrm{Q}$ for each microgrid is defined as:

$$
Q=w_{1} F+w_{2} E+w_{3} S
$$

Where, $F$ is a cost index of electricity, $E$ is an environmental effect index due to atmospheric emissions, and $\mathrm{S}$ is a load satisfaction. Q, F, E, and $\mathrm{S}$ are all between 0 and $1 . w_{i}$ $(\mathrm{i}=1,2,3)$ are weighting factors and $\sum w_{i}=1$. The ultimate objective for each MG is to maximize its overall performance index. 


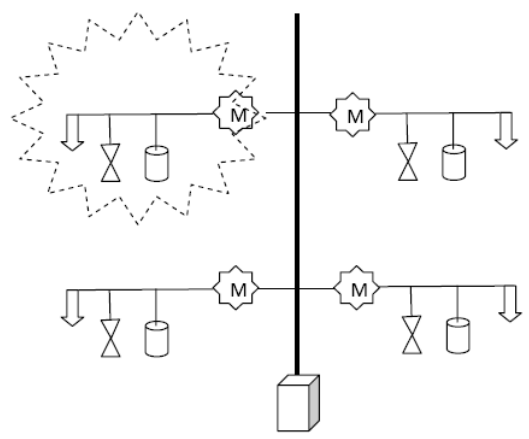

(a)

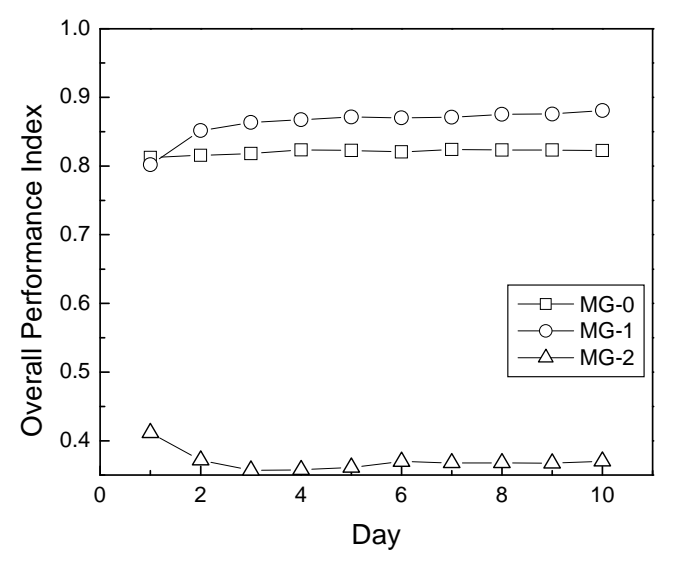

(b)

Figure 7 (a) a smart grid (b) the overall performance of three microgrids in a smart grid.

In this simulation, students can design their own microgrids to optimize the smart grid system and get the overall performance as in Figure 7(b).

\section{Conclusions}

In this paper, the sustainable-energy-related experiments are designed and the hardware and software are set up in the lab. Since the Spring semester in 2011 is the first semester that we offer the course, more feedbacks and improvements will be provided in the future. The setup of the lab and the manual are going to be uploaded on our website.

\section{Acknowledgement}

This work was supported by the US Department of Energy under DOE subaward no: A000211551

\section{References}

1. http://www.ece.umn.edu/groups/power/mat_lab.html.

2. https://analysis.nrel.gov/homer/. 